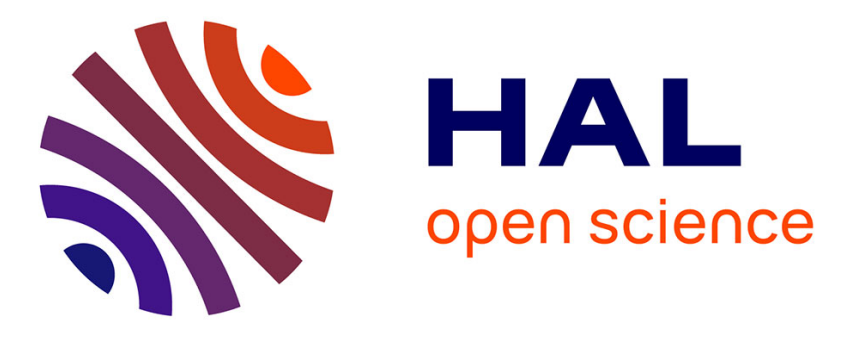

\title{
PTPN11 mutations in canine and human disseminated histiocytic sarcoma
}

Benoit Hedan, Mélanie Rault, Jérôme Abadie, Ronan Ulvé, Nadine Botherel, Patrick Devauchelle, Christiane Copie-Bergman, Edouard Cadieu, Marie Parrens, Julia Alten, et al.

\section{To cite this version:}

Benoit Hedan, Mélanie Rault, Jérôme Abadie, Ronan Ulvé, Nadine Botherel, et al.. PTPN11 mutations in canine and human disseminated histiocytic sarcoma. International Journal of Cancer, 2020, 147 (6), pp.1657-1665. 10.1002/ijc.32991 . hal-02534873

\section{HAL Id: hal-02534873 https://hal-univ-rennes1.archives-ouvertes.fr/hal-02534873}

Submitted on 27 Apr 2020

HAL is a multi-disciplinary open access archive for the deposit and dissemination of scientific research documents, whether they are published or not. The documents may come from teaching and research institutions in France or abroad, or from public or private research centers.
L'archive ouverte pluridisciplinaire HAL, est destinée au dépôt et à la diffusion de documents scientifiques de niveau recherche, publiés ou non, émanant des établissements d'enseignement et de recherche français ou étrangers, des laboratoires publics ou privés. 


\section{PTPN11 mutations in canine and human disseminated histiocytic sarcoma}

Benoit Hédan ${ }^{1 *}$, Mélanie Rault ${ }^{1 *}$, Jérôme Abadie${ }^{2}$, Ronan Ulvé ${ }^{1}$, Nadine Botherel ${ }^{1}$, Patrick Devauchelle ${ }^{3}$, Christiane Copie-Bergman ${ }^{4,5}$, Edouard Cadieu $^{1}$, Marie Parrens ${ }^{6}$, Julia Alten 7 , Emmanuelle Lechapt Zalcman ${ }^{8}$, Gunnar Cario ${ }^{7}$, Gandhi Damaj ${ }^{9}$, Karima Mokhtari ${ }^{10}$, Francois Le Loarer ${ }^{11}$, Aurore Coulomb-Lhermine ${ }^{12}$, Thomas Derrien ${ }^{1}$, Christophe Hitte ${ }^{1}$, Laura Bachelot ${ }^{1}$, Matthew Breen ${ }^{13}$, David Gilot ${ }^{1}$, Jean Yves Blay ${ }^{11}$, Jean Donadieu ${ }^{14}$ and Catherine André ${ }^{1}$

${ }^{1}$ CNRS-University of Rennes 1, UMR6290, Institute of Genetics and Development of Rennes, Faculty of Medicine, SFR Biosit, Rennes, France.

${ }^{2}$ Oniris, Laboniris - Department of Biology, Pathology and Food Sciences, Nantes, France. ${ }^{3}$ Micen Vet -Créteil, France.

${ }^{4}$ Assistance Publique-Hôpitaux de Paris, Département de Pathologie, Groupe HenriMondor Albert-Chenevier, Créteil F-94010, France.

5INSERM U955, équipe 9, Faculté de Médecine, Université Paris Est Créteil, Créteil F94010, France.

${ }^{6}$ Department of Pathology, CHU de Bordeaux, Hôpital du Haut Lévêque, Avenue Magellan, 33604 Pessac, INSERM U1035, Université de Bordeaux, France.

${ }^{7}$ Pediatric Oncology/Hematology, University Hospital Schleswig-Holstein, Campus Kiel, Arnold-Heller-Str.3, 24105 Kiel, Germany.

8 GHU Paris Psychiatrie Neurosciences, Sainte-Anne Hospital, Department of Neuropathology, 75014 Paris, France.

${ }^{9}$ Haemalology Institute, CHU de Caen and Centre François Baclesse, Caen, France.

${ }^{10}$ Sorbonne University, Inserm, CNRS, Institut du Cerveau et de la Moelle épinière, ICM, AP-HP, Hôpitaux Universitaires La Pitié Salpêtrière - Charles Foix, Service de Neuropathologie-Escourolle, Paris, France.

11Department of Medical Oncology, Centre Léon Bérard, Lyon, France.

12 Department of Pathology, Trousseau Hospital, Paris, France 
13 Department of Molecular Biomedical Sciences, College of Veterinary Medicine, North Carolina State University, CVM Research Building, 1060 William Moore Drive, Raleigh, NC 27607,USA.

${ }^{14}$ Department of Haematology, APHP, Trousseau Hospital, Paris, France.

* Benoit Hédan and Mélanie Rault should be considered joint first authors.

Novelty and Impact :

Due to its rarity, histiocytic sarcoma (HS) is not well known and treatment remains a challenge. Using the canine sponteanous model, we highlighted the association of PTPN11 somatic mutations to a disseminated subtype of HS in humans and dogs. Thanks to in-house canine HS cell lines, we tested MAP kinase inhibitors as a proof of concept of the interest of this model for the development and selection of efficient therapies.

List of abbreviations

HS: Histiocytic Sarcoma

MH: Malignant Histiocytosis

BMD: Bernese Mountain Dogs

LOH: Loss Of Heterozygozity

ctDNA: cell free circulating tumor DNA

\section{Abstract}

In humans, histiocytic sarcoma (HS) is an aggressive cancer involving histiocytes. Its rarity and heterogeneity explain that treatment remains a challenge. Sharing high clinical and histopathological similarities with human HS, the canine HS is conversely frequent in specific breeds and thus constitutes a unique spontaneous model for human HS to decipher the genetic bases and to explore therapeutic options. We identified sequence alterations in the MAPK pathway in at least $63.9 \%(71 / 111)$ of HS cases with mutually exclusive $B R A F(0.9 \% ; 1 / 111), K R A S$ (7.2\%; 8/111) and PTPN11 (56.75\%; 63/111) mutations concentrated at hotspots common to human cancers. Recurrent 
PTPN11 mutations are associated to visceral disseminated HS subtype in dogs, the most aggressive clinical presentation. We then identified PTPN11 mutations in 3/19 (15.7\%) human HS patients. Thus, we propose PTPN11 mutations as key events for a specific subset of human and canine HS: the visceral disseminated form. Finally, by testing drugs targeting the MAPK pathway in eight canine HS cell lines, we identified a better antiproliferation activity of MEK inhibitors than PTPN11 inhibitors in canine HS neoplastic cells. In combination, these results illustrate the relevance of naturally affected dogs in deciphering genetic mechanisms and selecting efficient targeted therapies for such rare and aggressive cancers in humans.

\section{Introduction}

Histiocytic sarcomas (HS), also referred as Malignant Histiocytosis (MH), are rare tumors characterized by proliferation of cells with the phenotype of mature tissue histiocytes ${ }^{1}$. Half of the cases occur in the context of a previous lymphoid or myeloid neoplasm, while the other half are considered as primitive proliferation of histiocytes ${ }^{1}$. This aggressive tumor leads to a high mortality and currently there is neither consensus on prognostic factors, nor on standard treatment. Recent publications showed that the MAPK pathway, with $B R A F$ alterations, plays a crucial role in the development of $\mathrm{HS}^{2-6}$. Drugs targeting this pathway such as vemurafenib or sorafenib have shown clinical responses in HS cases ${ }^{7,8}$. The rarity and heterogenous nature of this cancer poses significant challenges to advancing knowledge, limiting opportunities to identify recurrent alterations with driver roles and aiding selection of targeted therapies.

Interestingly, this tumor type, occurring naturally and well-characterized in the domestic dog, is especially prevalent (up to 20\%) in some popular predisposed breeds, including Bernese mountain dogs (BMD), rottweilers and retrievers ${ }^{9-11}$. Genetic predispositions in these breeds have led to the availability of many naturally affected cases with homogeneous clinical presentation in a specific canine breed ${ }^{9,10}$. Indeed, BMDs more frequently display disseminated HS with simultaneous involvement of 
multiple internal organs at time of diagnosis, whereas retrievers more often develop localized HS with tumor initially restricted to joint, muscle or subcutaneous tissue. Using this unique resource to characterize HS, we identified recurrent gain-of-function mutations in the MAPK pathway in canine and then in human HS. The PTPN11 mutations - the main recurrent alterations in canine HS (56.75\%; 63/111)- are associated with the visceral disseminated canine HS subtype. We thus proposed that PTPN11 mutations are also characteristic of a visceral disseminated form of human HS. By developing seven canine HS in-house cell lines, we tested drugs targeting directly PTPN11 or the MAPK pathway and confirmed the antitumor activity of MEK inhibitors in canine HS neoplastic cells, illustrating the potential of the dog model to screen drugs to improve therapies of this rare and aggressive cancer. 


\section{Material \& Method}

\section{Sample collection}

Blood and tissue biopsy samples from dogs were collected by veterinarians through the Cani-DNA BRC (http://dog-genetics.genouest.org) and DNA/RNA was extracted as previously described ${ }^{12}$. Blood was also collected on Cell-free DNA BCT (Streck, La Vista, Nebraska, USA) and cell-free circulating DNA was extracted with NucleoSnap® DNA Plasma (Macherey Nagel, Düren, Germany) according to the manufacturer protocol. The canine HS cases were diagnosed by histopathological analysis (JA) with adequate immunostaining (CD204 SRA-E5 Abcam MAB1710).

Seventeen human DNA samples were collected through the French Histiocytosis Registry, approved by the Comité de Protection des Personnes Ile de France III (\#2011A00447-34) over a fifteen-year period (2003-2018). Diagnosis of primary HS was established according to the classification of histiocytosis ${ }^{1}$ and cases were independently reviewed by experienced human pathologists. DNA was extracted either from FFPE tissues or from snap frozen tissue biopsies samples, part of them by the Department of Pathology (APHP University Hospital Ambroise Paré, Boulogne, France) thanks to Jean-Francois Emile. Two additional cases were obtained from the literature ${ }^{13}$ (Table 1).

\section{Sequencing}

RNA-Seq and Sanger sequencing were performed on canine samples as previously described $^{12}$. For all mutations, their somatic status was assessed with the corresponding constitutional DNAs. Human DNA libraries for PTPN11 sequencing were prepared by targeted enrichment and amplicon tagging (Access array barcode - Fluidigm, San Francisco, USA). When high quality and quantity DNA samples were available, BRAF and KRAS hot spots were also amplified. The libraries were sequenced by MiSeq following 
Illumina's protocol (sequencing platform GEH, Biosit, Rennes). Primers are available in Supplementary Table 1.

\section{Cell lines}

The 8 cell lines include one commercial cell line (DH82 (ATTC CRL-10389; RRID:CVCL_2018) and seven cell lines developed in the team from HS affected dog fresh tissues (supplementary table 2). These seven cell lines are available on request. Cells were cultivated in a complete RPMI medium containing RMPI 1640 GlutaMAX supplemented medium (Gibco. life technologies) with 10\% of Fetal Bovine Serum (HyClone, GE Healthecare, Life ScienceS, Logan, USA) and 0,025\% of Primocin (InvivoGen, Toulouse France) at $37{ }^{\circ} \mathrm{C}$ in a humidified 5\% CO2 incubator. All cell lines were tested for mycoplasma with MycoAlert ${ }^{\mathrm{TM}}$ Plus kit (Lonza; Rockland; ME; USA) and were mycoplasma-free cells.

\section{Drug tests on canine HS cell lines}

We tested four drugs targeting the MAPK pathway: U0126 (Promega Co., Madison, USA), GS-493, kindly provided by Dr Birchmeier and Dr Land, Sorafenib (Santa Cruz Biotechnology Inc., Dallas, USA) and Trametinib (Active Biochemicals Co., Hong Kong). Stock solutions of drugs were made in DMSO. The cells were cultured for $24 \mathrm{~h}$ in 96 -well plates and the drug or the DMSO alone was then added for additional $72 \mathrm{H}$. Six biological replicates were used for each drug concentration tested, and 12 replicates for the DMSO controls. Cell proliferation was evaluated by methylene blue assays. A Dixon test was performed for each replicate and the proliferation rate was normalized with the DMSO control for each cell line. IC25s were fitted by non-linear regression (Weibull equation, maximum 1, minimum estimated) using the GraphPad Prism version 6.00 (GraphPad Software, La Jolla California USA).

\section{Statistical analyses}


Statistical analyses were performed using the R software (Vienna, Austria). Fisher's Exact tests were used to evaluate the association between PTPN11 mutations and clinical parameters, Wilcoxon Mann Whitney test was used to compare IC25 distribution between homozygous and heterozygous PTPN11 mutated cell lines. Values of $p<0.05$ were considered statistically significant.

\section{Data availability}

RNA-seq data are available at European Nucleotide Archive (accession number: PRJEB36828). Other data will be made available upon reasonable request.

Material \& Method for the primer design, the Western-blots, the Cytogenetic and LOH analyses are available in Supplementary Material \& Method.

\section{Results}

To characterize somatic alterations in histiocytic sarcomas, we performed RNASeq on three canine HS cases and the commercial cell line DH82 and we identified two somatic mutations in PTPN11. These two mutations are homologous to the human PTPN11 E76K and G503V mutations occurring in hotspot regions of this gene in human cancers (COSMIC database) ${ }^{14}$. To estimate the frequency and analyze the relevance of PTPN11 mutations, and more widely of the MAPK pathway involvement in HS oncogenic events, we searched for the presence and recurrence of somatic mutations in PTPN11, KRAS, NRAS, HRAS, BRAF and CBL in all 111 canine HS cases. All tumors except one were found wild-type for BRAF. This $B R A F$-mutated case presented two mutations orthologous to human S465T and G469A BRAF mutations. We found PTPN11 and KRAS somatic mutations in $56,7 \%(63 / 111)$ and $7.2 \%(8 / 111)$ of cases respectively, indicating alterations of the MAPK pathway in 63.9\% of canine HS (Figure 1 and Supplementary Table 2). These mutations were mutually exclusive in all but one case, a composite heterozygous case. We found that PTPN11 mutations were enriched, but not significantly, in the BMD breed (58.8\% vs $47.6 \%$ p-value $=0.46$, Fisher's Exact test), in 
agreement with the recent identification of the PTPN11 mutations in canine HS associated with BMD ${ }^{15}$. In our large canine cohort, we identified an association between PTPN11 somatic mutations and the internal localization of tumors or HS disseminated forms ( $\mathrm{p}$-value $=1.27 \times 10^{-4}$, and p-value $=1.6 \times 10^{-6}$ respectively, Fisher's Exact test). These results indicate that PTPN11 mutations are associated with the aggressive form of disseminated HS rather than the localized HS forms in dogs.

These mutations in the PTPN11 protein in canine HS are distributed at two hotspots, identical to those observed in human cancers (Figure $1 \mathrm{~B}$ ) and inducing overactivation of PTPN11 in juvenile myelo-monocytic leukemia ${ }^{16}$. As expected with the strong sequence identity (99\%) between the human and canine PTPN11 proteins, these gain-of-function mutations in dogs are also associated with MAPK pathway activation ${ }^{15}$. By Western Blot analyses, we confirmed the constitutive activation of the MAPK pathway (pERK) in 2 HS cell lines harboring PTPN11 mutations (Supplementary Figure 1).

Moreover, with the high incidence of this tumor in dogs, this natural model allows to study the life history of HS and the timing of PTPN11 mutations in disseminated HS. Using CGH and Loss of Heterozygozity (LOH) analyses of 13 tumor samples from five dogs presenting with several histiocytic masses, we showed that 4/5 cases had a common origin with a clonal linear evolution, demonstrating the metastatic origin of disseminated HS (Figure 2, Supplementary Figure 2). For the one case presenting different CGH profiles between lung tumor and spleen/lymph node tumors, the $\mathrm{LOH}$ analysis is in favor of a common origin of disseminated HS ( $\mathrm{P}_{\text {chromosome }}=0.0058$ and $P_{\text {marker }}=0.0022$ ) with subsequent genetic divergence (Supplementary Table 4). This case suggests that PTPN11 mutations probably occur in late stages of the tumor.

Considering the high frequency of the PTPN11 gain-of-function mutations in disseminated canine HS, we hypothesize that PTPN11 mutations can also be a key event in a subset of human HS. We then explored the frequency of PTPTN11 mutations in 19 
human MH cases with visceral masses. Using high throughput sequencing, we identified PTPN11 mutations in three cases (Table 1). Interestingly, the recent report of Shanmugman et al. (2019), identifying two PTPN11 mutations in two patients with internal and multifocal tumors, confirmed that PTPN11 mutations are enriched in visceral disseminated cases ( $p$-value $=0.0476$ one sided Fisher's Exact Test $)^{5}$. Moreover, Egan et al. (2019) recently showed the existence of a distinct subtype of primary HS characterized by PTPN11 alterations enriched in gastrointestinal tract localizations ${ }^{17}$. Altogether, these results strongly suggest that PTPN11 mutations drive the growth of histiocytic neoplasms in humans as in dogs. Moreover, the canine data highlight that the key PTPN11 mutations are associated with visceral dissemination and aggressiveness of HS. For four samples with enough available DNA, we also explored BRAF and KRAS hotspots, previously found exclusively mutated with PTPN11 in canine HS. Interestingly, in WT-PTPN11 human patients, we identified two KRAS mutations (G12D and Q61H) and one BRAF mutation (G464V) (Table 1). While the number of cases is limited, our results and the literature confirmed our hypotheses that PTPN11 mutations, as BRAF and KRAS mutations are a key mechanism of the MAPK pathway activation, playing a crucial role in the physiopathology of HS in humans and dogs.

The identification of driver events is a key step in proposing targeted therapies, as shown by Diamond et al. who demonstrated the clinical efficacy of MEK and RAF inhibitors on MAP2K1- and ARAF-mutated Histiocytic Neoplasms ${ }^{7}$. We thus proposed the spontaneous disseminated form of canine HS as a relevant model to evaluate candidate drugs for treating human PTPN11-mutated HS patients. Thus, we developed seven canine in-house HS cell lines. These cell lines as well as the commercial cell line DH82 were all mutated for PTPN11 (homozygous or heterozygous state); one cell line was also heterozygous for the KRAS Q61H mutation (Supplementary Table 3). We studied their sensitivity, together with the DH82 cell line, to three drugs targeting the MAPK pathway. Based on the development of personalized medicine and interest of targeting PTPN11 in human cancers $^{18}$, we tested a PTPN11 inhibitor, GS-493, expected 
to inhibit the phosphatase activity in PTPN11 gain of fonction mutant ${ }^{19}$. We compared it with Trametinib and Sorafenib, two FDA-approved drugs with clinical efficacy in human histiocytic neoplasms ${ }^{7}$. The three inhibitors decreased the cell density for all cell lines (Figure 3). Homozygous or compound heterozygous PTPN11 mutated cell lines were more sensitive to the PTPN11 inhibitor GS-493 than heterozygous cell lines (p-value= 0.02857 One Sided Wilcoxon Mann Whitney test). However, the highest sensitivity to inhibitors was observed with Trametinib (IC25 $=3,01.10^{-3} \mu \mathrm{M} ; \pm 5,10.10^{-3} \mu \mathrm{M}$ ) (Supplementary Table 5).

Based on the PTPN11 and KRAS mutations detected in the BRAF wild type canine HS, we confirmed that targeting the RAF/RAS/MEK pathway with MEK inhibitors such as Trametinib is a promising therapeutic option for patients with histiocytic sarcoma especially disseminated cases, harboring PTPN11 mutations. These results emphasize the relevance of the canine spontaneous model for the selection of more efficient therapies.

\section{Discussion}

Comparative oncology across species appears useful to identify driver molecular alterations in similar nosological entities, and may guide research for both species, which could prove extremely useful for rare human cancers. The present complementary approach is based on large cohorts and identifies PTPN11 mutations both in frequent canine and rare human aggressive histiocytic sarcoma. Our results demonstrated the association of PTPN11 mutations with disseminated canine HS, the most aggressive subtype, and highlighted that human patients harboring PTPN11 mutations also share a similar disseminated clinical presentation. Our results expand the current understanding of the pathogenesis of histiocytic neoplasms and offer new opportunities for the comprehension of the genetic mechanisms. They also provide clues to new therapeutic approaches for the mutual benefit of human and veterinary medicine. Last, this approach, using naturally affected dogs, in a non-experimental 
frame, is respectful of the ethics and of the 3R rule, by replacing experimental animals by pet dogs in the frame of their health care.

Through a unique series of 111 canine HS cases, we showed the high prevalence of PTPN11 mutations at the two key hot spots (56.75\%) and that these alterations are linked to an aggressive HS subtype. This work confirmed the recent identification of PTPN11 mutations in canine HS associated to the BMD breed ${ }^{15}$. In our cohort, we detected a more significant association with the visceral disseminated HS forms than with the breed, due to the fact that BMD is mainly affected by disseminated HS form ${ }^{10}$. The link between PTPN11 mutations and an aggressive clinical presentation of this histiocytic neoplasm is supported by the identification of three PTPN11 mutations in human cases with internal tumors as well as cases from the literature: except for one case with "unspecified lymph node" localization, all published human cases to date (10 cases), with PTPN11 somatic alterations presented internal masses, including kidney, spleen or brain localizations $4,5,17,20-22$. Moreover the mutated patients presented multifocal masses with dramatic evolution similar to canine disseminated HS,5,20-22. Finally, the recent work of Egan et al. clearly showed that human HS cases with PTPN11 alterations form a distinct subtype of primary HS with predilection to gastrointestinal tract ${ }^{17}$, these recent results reinforcing our work. Altogether, our data refined our comprehension of the genetic bases of HS in dogs and humans, by associating PTPN11 mutations to an aggressive clinical presentation associated to internal/visceral masses. In this study, we also identified mutations exclusive to PTPN11 in the same hotspots of $K R A S$ and $B R A F$ in canine and human HS cases, confirming the driving role of these KRAS and $B R A F$ mutations in histiocytic neoplasms as previously shown ${ }^{4,5,17,20-23}$. Noticeably, the $B R A F$ mutations identified in canine and human HS cases were found in the GSGSFG phosphate binding loop (P-loop) at residues 464-469 and constitute novel relevant mutations since this region, with the V600 region, contain the majority of BRAF mutations in human cancers ${ }^{24}$. 
The attractiveness of the spontaneous canine model, is based on the higher HS frequency due to a strong breed predisposition ${ }^{10,11}$ and clinical homogeneity, recapitulating the clinical presentations of primary human HS. This model thus offers a great potential to decipher the genetic mechanisms involved in rare human clinical subtypes and also to screen for targeted therapies. Previous studies orientated treatments towards MEK inhibition in canine and in human HS7,20,25,26. In the context of PTPN11 alterations, we tested a specific PTPN11 inhibitor, which surprisingly was, invitro, less efficient than MEK inhibitors. Interestingly, one cell line (Dog-HS-13281) is clearly more sensitive to the tested inhibitors probably due to the presence of KRAS complementary mutation (Supplementary table 4). Future studies are needed to explore the targeted therapies, especially in case of partial ${ }^{20}$ or refractory responses ${ }^{8}$. The mechanisms of resistance, only explored to date in one patient ${ }^{5}$, are expected especially if the MAPK pathway activation with PTPN11 mutations occurs at a late stage of tumoral development as suggested by our results. We hypothesize that this late event leads to HS dissemination but further studies are needed to exclude that PTPN11 mutated HS could represent a different nosological entity with a specific origin of histiocytes than PTPN11 wild-type HS. Last, we succeeded in detecting PTPN11 mutations in cell free circulating tumor DNA (ctDNA) of canine cases (Supplementary Table 2). Thus the spontaneous canine HS model, with the availability of numerous cases and the possibility of therapeutic response follow-up with the ctDNA is a unique opportunity to explore therapeutic options and resistance mechanisms through in vitro screening in canine HS cell lines and in vivo pre-clinical trials in pet dogs.

In conclusion, through access to a large cohort of canine HS, we identified MAPK pathway-activating PTPN11 mutations, which point out a specific aggressive disseminated HS subgroup in dogs and in humans. We propose that the key PTPN11 mutations occur in late stage of tumorigenesis with tumoral dissemination. Our findings strongly advocate the rationale for MAPK inhibition in BRAF-wild-type HS cases and we propose to take advantage of the unique resource of canine cases to screen inhibitor 
efficiency as has already been done in integrated approaches with pet dogs clinical trials ${ }^{27}$. Finally, this work confirms the value of naturally occurring canine cancers as models for the study of rare human cancers from the discovery of mutations to the development and the screening of targeted therapies.

\section{Acknowledgments}

We thank Olivier Albaric and Laetitia Dorso (Laboniris, Oniris, Ecole Nationale Vétérinaire de Nantes, France) as well as Marie-Odile SEMIN (LAPV, Amboise, France), Caroline Laprie (Vet-Histo, Marseille, France), Marie Lagadic (Idexx Alfort, France), Frédérique Degorce-Rubiale (LAPVSO, Toulouse, France) who provided veterinarian anatomopathologic diagnoses. We thank the veterinarians for providing us with clinical data and samples, as well as dog owners, breeders and breed clubs, especially the French club AFBS, European clubs, the American club BMDCA, the IWG International Working Group (for Bernese Mountain Dogs) and the US Berner garde foundation, especially Pat Long for her dedicated trust and follow-up of our work.

We also warmly thank Dr Frédéric Charlotte (CHU Pité-Salpêtrière, Paris, France), Pr Nicole Brousse (Necker Hospital, Paris, France), Dr Claire Danel (Bichat Hospital, Paris, France), Dr Virginie Verkarre and Dr Sylvie Fraitag (Necker Hospital, Paris, France), Dr Anne Moreau (Nantes Hospital, France) and Dr Catherine Chassagne-Clement (Unicancer, Lyon, France) who provided human anatomopathologic diagnoses. We warmly thank Wouters Coppieters, Anne-Sophie Lequarré and Michel Georges (GIGAGenomics, Université de Liège, Belgique) for RNA-Seq facilities, Stéphane Dréano (IGDR, Rennes, France) for Sanger sequencing and the Biogenouest bioinformatic platform. We warmly thank the Reference Center for Histiocytoses, France who kindly provided FFPE samples of patients. We warmly thank Dr W. Birchmeier and Dr L. Land (Max Delbrueck Center for Molecular Medicine, Berlin, Allemagne) who kindly provided GS-493. We 
thank Alexandra Lespagnol (CHU Rennes, France), for scientific advices on circulating DNAs.

\section{Supports}

This study was supported by CNRS and INCa PLBio "canine rare tumours" funding $\left(\mathrm{N}^{\circ}\right.$ 2012-103; 2012-2016), in the frame of the Plan Cancer 2009-2013, by the CRB-Anim infrastructure ANR-11-INBS-0003 and in the frame of the 'Investing for the Future Program (PIA) for the Cani-DNA BRC and by AKC CHF funding ( $\mathrm{N}^{\circ} 1557,2446$ and 2667). Mélanie Rault, PhD was funded through a French "Ministère de la recherche" funding (2013-2016).

\section{Author's Contributions}

Conception and design: B. Hedan, M.Rault, J. Donadieu, C. André

Development of methodology: B. Hedan, M. Rault, R. Ulve, E. Cadieu

Acquisition of data (provided animals, acquired and managed patients, provided facilities, etc.): B. Hedan, M. Rault, R. Ulve, J. Abadie, N. Botherel, L. Bachelot, D. Gilot, , J. Donadieu, K. Mokhtari, MC.Parrens, G. Damaj, C. Copie , E. Lechapt Zalcman, F. Le Loarer, M. Breen, P. Devauchelle, G. Cario, J. Alten. A. Coulomb-Lhermine.

Analysis and interpretation of data (e.g., statistical analysis, biostatistics, computational analysis): B. Hédan, M. Rault, C. Hitte, T. Derrien, C. André

Writing, review, and/or revision of the manuscript: B. Hedan, M. Rault, C. André , J. Donadieu, D. Gilot, JY. Blay, M. Breen.

\section{Disclosure of Conflicts of Interest}

No conflicts of interest 


\section{References}

1. Emile J-F, Abla O, Fraitag S, Horne A, Haroche J, Donadieu J, Requena-Caballero L, Jordan MB, Abdel-Wahab O, Allen CE, Charlotte F, Diamond EL, et al. Revised classification of histiocytoses and neoplasms of the macrophage-dendritic cell lineages. Blood 2016;127:2672-81.

2. Go H, Jeon YK, Huh J, Choi SJ, Choi Y-D, Cha HJ, Kim H-J, Park G, Min S, Kim JE. Frequent detection of BRAF(V600E) mutations in histiocytic and dendritic cell neoplasms. Histopathology 2014;65:261-72.

3. Kordes M, Roring M, Heining C, Braun S, Hutter B, Richter D, Georg C, Scholl C, Groschel S, Roth W, Rosenwald A, Geissinger E, et al. Cooperation of BRAF and mutant HRAS in histiocytic sarcoma provides new insights into oncogenic BRAF signaling. Leukemia 2015;

4. Liu Q, Tomaszewicz K, Hutchinson L, Hornick JL, Woda B, Yu H. Somatic mutations in histiocytic sarcoma identified by next generation sequencing. Virchows Arch Int J Pathol 2016;

5. Shanmugam V, Griffin GK, Jacobsen ED, Fletcher CDM, Sholl LM, Hornick JL. Identification of diverse activating mutations of the RAS-MAPK pathway in histiocytic sarcoma. Mod Pathol Off J U S Can Acad Pathol Inc 2019;

6. Michonneau D, Kaltenbach S, Derrieux C, Trinquand A, Brouzes C, Gibault L, North M-O, Delarue R, Varet B, Emile J-F, Brousse N, Hermine O. BRAF(V600E) mutation in a histiocytic sarcoma arising from hairy cell leukemia. J Clin Oncol Off J Am Soc Clin Oncol 2014;32:e117-21.

7. Diamond EL, Durham BH, Haroche J, Yao Z, Ma J, Parikh SA, Wang Z, Choi J, Kim E, Cohen-Aubart F, Lee SC-W, Gao Y, et al. Diverse and Targetable Kinase Alterations Drive Histiocytic Neoplasms. Cancer Discov 2016;6:154-65.

8. Idbaih A, Mokhtari K, Emile J-F, Galanaud D, Belaid H, de Bernard S, Benameur N, Barlog V-C, Psimaras D, Donadieu J, Carpentier C, Martin-Duverneuil N, et al. Dramatic response of a BRAF V600E-mutated primary CNS histiocytic sarcoma to vemurafenib. Neurology 2014;83:1478-80.

9. Abadie J, Hedan B, Cadieu E, De Brito C, Devauchelle P, Bourgain C, Parker HG, Vaysse A, Margaritte-Jeannin P, Galibert F, Ostrander EA, Andre C. Epidemiology, pathology, and genetics of histiocytic sarcoma in the Bernese mountain dog breed. $J$ Hered 2009;100 Suppl 1:S19-27.

10. Hedan B, Thomas R, Motsinger-Reif A, Abadie J, Andre C, Cullen J, Breen M. Molecular cytogenetic characterization of canine histiocytic sarcoma: A spontaneous model for human histiocytic cancer identifies deletion of tumor suppressor genes and highlights influence of genetic background on tumor behavior. BMC Cancer 2011;11:201. 11. Shearin AL, Hedan B, Cadieu E, Erich SA, Schmidt EV, Faden DL, Cullen J, Abadie J, Kwon EM, Grone A, Devauchelle P, Rimbault M, et al. The MTAP-CDKN2A locus confers susceptibility to a naturally occurring canine cancer. Cancer Epidemiol Biomark Prev Publ Am Assoc Cancer Res Cosponsored Am Soc Prev Oncol 2012;21:1019-27.

12. Ulve R, Rault M, Bahin M, Lagoutte L, Abadie J, De Brito C, Coindre J-M, Botherel N, Rousseau A, Wucher V, Cadieu E, Thieblemont C, et al. Discovery of human-similar gene 
fusions in canine cancers. Cancer Res 2017;

13. Alten J, Klapper W, Leuschner I, Eckert C, Beier R, Vallo E, Krause M, Claviez A, Vieth S, Bleckmann K, Moricke A, Schrappe M, et al. Secondary histiocytic sarcoma may cause apparent persistence or recurrence of minimal residual disease in childhood acute lymphoblastic leukemia. Pediatr Blood Cancer 2015;62:1656-60.

14. Bamford S, Dawson E, Forbes S, Clements J, Pettett R, Dogan A, Flanagan A, Teague J, Futreal PA, Stratton MR, Wooster R. The COSMIC (Catalogue of Somatic Mutations in Cancer) database and website. Br J Cancer 2004;91:355-8.

15. Takada M, Smyth LA, Thaiwong T, Richter M, Corner SM, Schall PZ, Kiupel M, Yuzbasiyan-Gurkan V. Activating Mutations in PTPN11 and KRAS in Canine Histiocytic Sarcomas. Genes 2019;10.

16. Rehman AU, Rahman MU, Khan MT, Saud S, Liu H, Song D, Sultana P, Wadood A, Chen H-F. The Landscape of Protein Tyrosine Phosphatase (Shp2) and Cancer. Curr Pharm Des 2018;24:3767-77.

17. Egan C, Nicolae A, Lack J, Chung H-J, Skarshaug S, Pham TA, Navarro W, Abdullaev Z, Aguilera NS, Xi L, Pack S, Pittaluga S, et al. Genomic profiling of primary histiocytic sarcoma reveals two molecular subgroups. Haematologica 2019;

18. Prahallad A, Heynen GJJE, Germano G, Willems SM, Evers B, Vecchione L, Gambino V, Lieftink C, Beijersbergen RL, Di Nicolantonio F, Bardelli A, Bernards R. PTPN11 Is a Central Node in Intrinsic and Acquired Resistance to Targeted Cancer Drugs. Cell Rep 2015;12:1978-85.

19. Grosskopf S, Eckert C, Arkona C, Radetzki S, Bohm K, Heinemann U, Wolber G, von Kries J-P, Birchmeier W, Rademann J. Selective inhibitors of the protein tyrosine phosphatase SHP2 block cellular motility and growth of cancer cells in vitro and in vivo. ChemMedChem 2015;10:815-26.

20. Voruz S, Cairoli A, Naveiras O, de Leval L, Missiaglia E, Homicsko K, Michielin O, Blum S. Response to MEK inhibition with trametinib and tyrosine kinase inhibition with imatinib in multifocal histiocytic sarcoma. Haematologica 2018;103:e39-41.

21. Batra S, Martin SC, Nassiri M, Qureshi A, Markel TA. Histiocytic Sarcoma Associated with Coombs Negative Acute Hemolytic Anemia: A Rare Presentation. Case Rep Oncol Med 2016;2016:3179147.

22. Zhang Q, Shibani A, Sadikovic B, Howlett CJ, Ang L-C. An aggressive multifocal primary CNS histiocytosis with PTPN11 (Shp2) mutation. Neuropathol Appl Neurobiol 2018;44:240-3.

23. Goyal G, Lau D, Nagle AM, Vassallo R, Rech KL, Ryu JH, Davidge-Pitts CJ, Tobin WO, Koster MJ, Bennani NN, Shah MV, Liu MC, et al. Tumor mutational burden and other predictive immunotherapy markers in histiocytic neoplasms. Blood 2019;133:1607-10. 24. Holderfield M, Deuker MM, McCormick F, McMahon M. Targeting RAF kinases for cancer therapy: BRAF-mutated melanoma and beyond. Nat Rev Cancer 2014;14:455-67. 25. Gounder MM, Solit DB, Tap WD. Trametinib in Histiocytic Sarcoma with an Activating MAP2K1 (MEK1) Mutation. N Engl J Med 2018;378:1945-7.

26. Takada M, Hix JML, Corner S, Schall PZ, Kiupel M, Yuzbasiyan-Gurkan V. Targeting MEK in a Translational Model of Histiocytic Sarcoma. Mol Cancer Ther 2018;17:2439-50. 
27. Paoloni M, Khanna C. Translation of new cancer treatments from pet dogs to humans. Nat Rev Cancer 2008;8:147-56. 


\section{Figure and table legends}

Figure 1: MAPK alterations in canine HS. A) Landscape of somatic mutations of several MAPK oncogenes in 111 cases of canine HS. PTPN11 hotspots are mutated in 56,75\% of the 111 cases of canine HS (63/111), KRAS hotspots are mutated in $7.2 \%$ of the cases (8/111), BRAF is mutated in $0.9 \%$, while no mutation is found in HRAS, NRAS or $C B L$ hotspots. B) Distribution of PTPN11 mutations along the protein sequence in the canine HS cases compared to the PTPN11 mutations reported for human cancers (COSMIC database).

Figure 2: Hierarchical clustering of disseminated histiocytic sarcomas from five dogs. A) The algorithm summarizes relationships between the genomic aberrations of different tumors detected by CGH data in a dendrogram, in which pattern and length of the branches reflect the relatedness of samples. B) CGH profile of sarcoma cases: larger pictures of CGH profiles are available in supplementary Figure 2. C) PTPN11 mutations. Mutations detected by Sanger sequencing are indicated by *. The mutations PTPN11G503V , PTPN11 ${ }^{\mathrm{E} 76 \mathrm{G}}$ and PTPN11 ${ }^{\mathrm{G} 60 \mathrm{D}}$ were detected in Case 2, Case 3 and Case 5 respectively. The PTPN11 ${ }^{\mathrm{E} 76 \mathrm{G}}$ was detected in the lung of Case 4 while $P T P N 11^{\mathrm{E} 76 \mathrm{~K}}$ was detected in the spleen and lymph node tumors of Case 4.

Figure 3: Inhibitory effect of U0126, GS-493, Sorafenib and Trametinib on $72 \mathrm{~h}$ cell proliferation of eight canine HS cell lines. All the cell lines are sensitive to the four inhibitors, with a higher sensitivity for the Trametinib. 
Table 1: Human HS cases Summary. Cases were collected through the Reference Center for Histiocytoses, France and from the literature. Somatic alterations detected by NGS are indicated: mutations of PTPN11 according to ENST00000351677, mutations of KRAS according to ENST00000256078.9, mutations of BRAF according to ENST00000496384.7. 


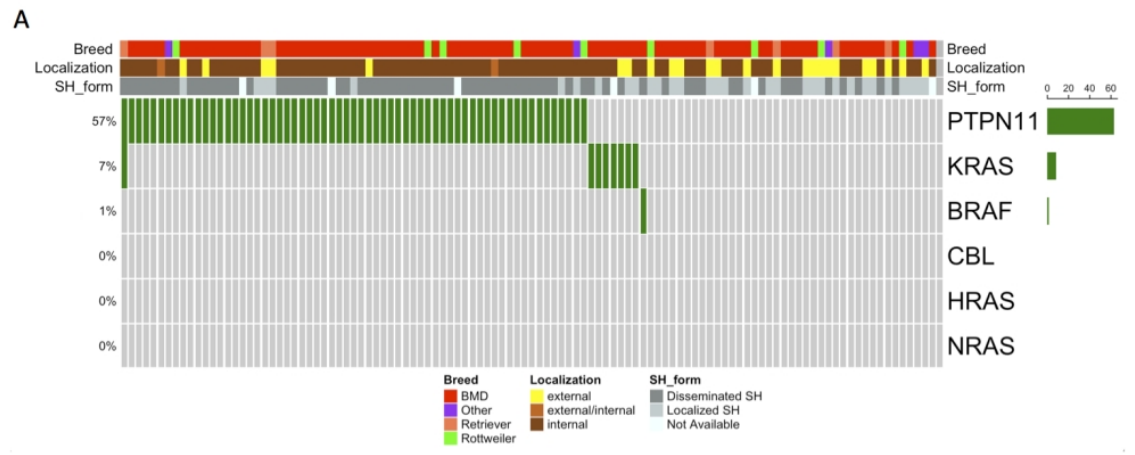

B

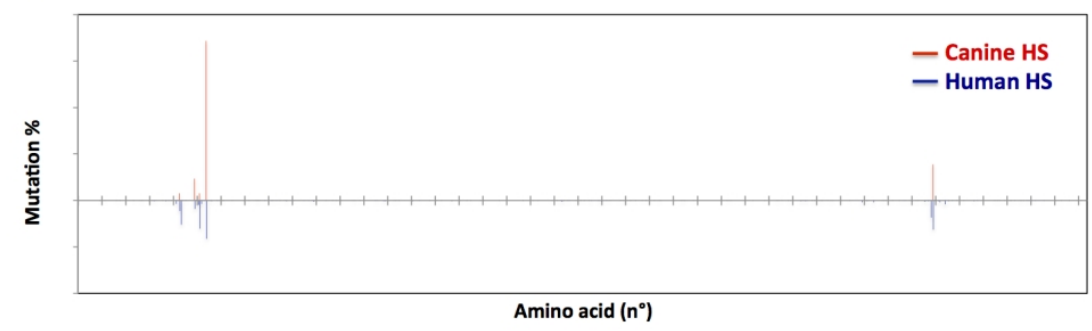


A

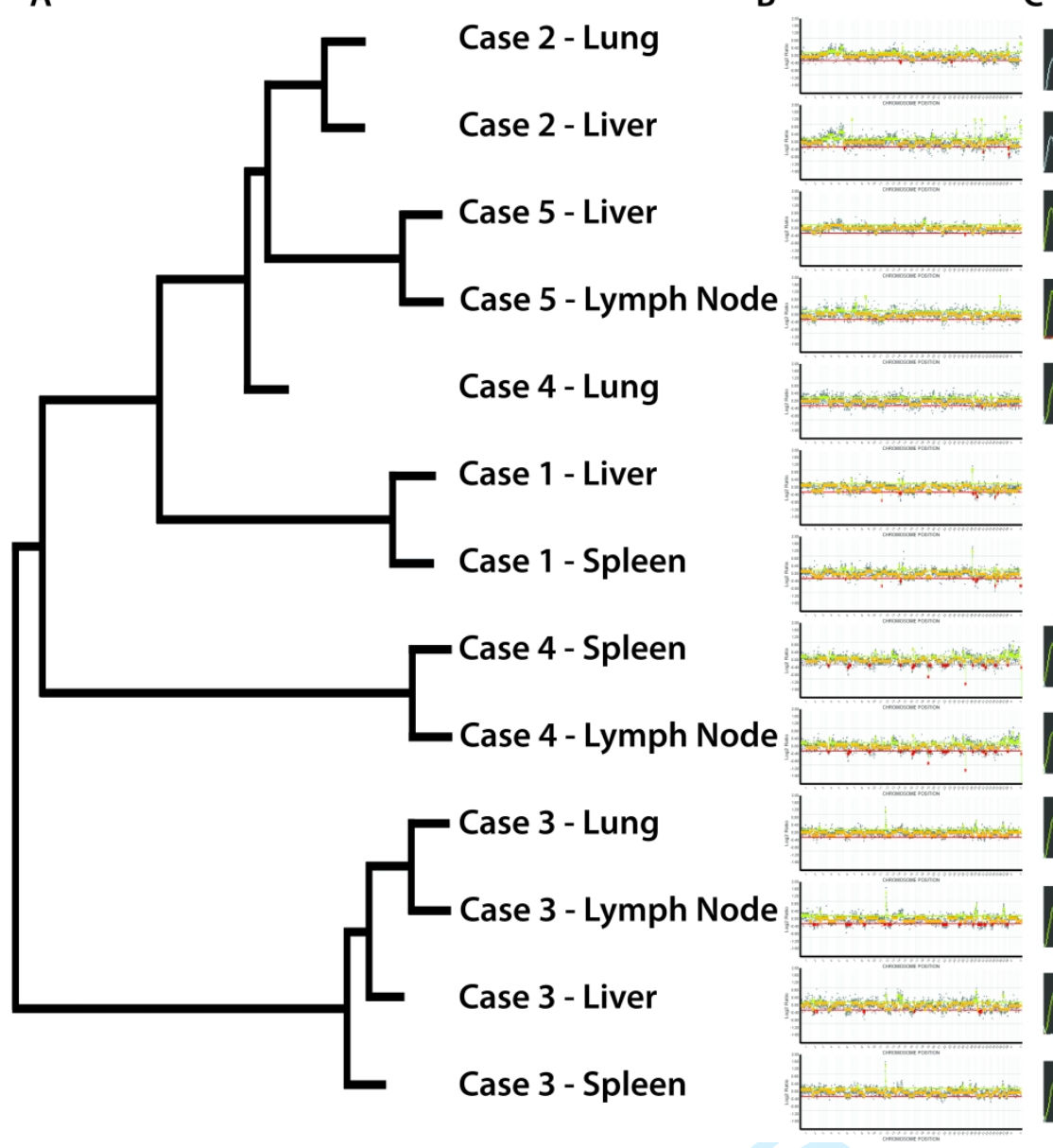

C
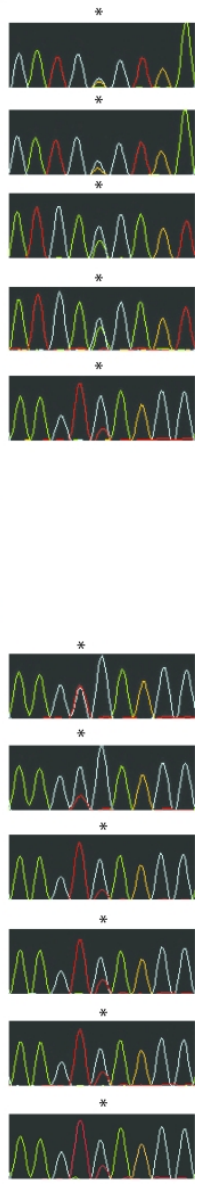
U0126

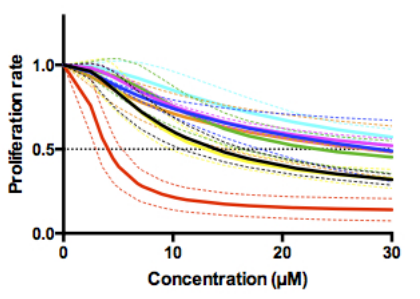

GS-493

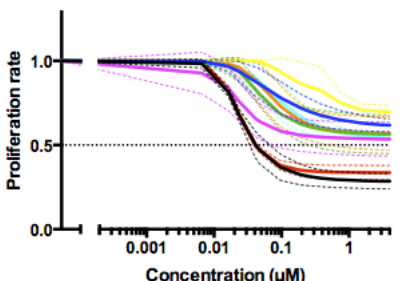

Sorafenib
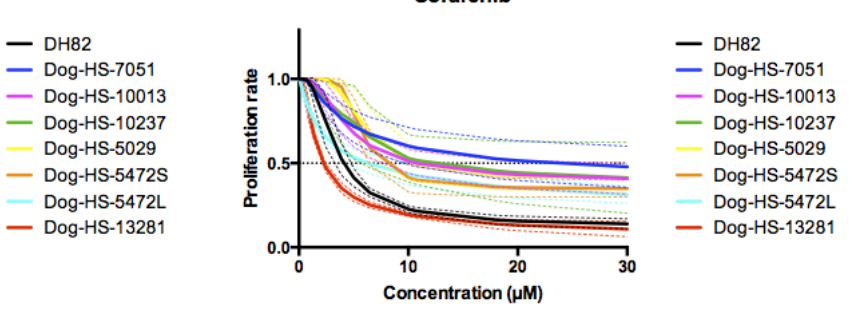

Trametinib

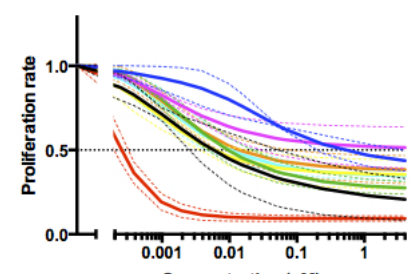

- DH82

— Dog-HS-7051

- Dog-HS-10013

- Dog-HS-10237

Dog-HS-5029

- Dog-HS-5472S

- Dog-HS-5472L

- Dog-HS-5472L

— Dog-HS-13281

Concentration $(\mu \mathrm{M})$ 


\begin{tabular}{|c|c|c|c|c|c|c|c|c|c|}
\hline Case No. & Age (years) & Sex & Tumor site & $\begin{array}{l}\text { Outcome, } \\
\text { follow-up }\end{array}$ & $\begin{array}{l}\text { Prior/concurrent } \\
\text { hematologic } \\
\text { malignancy }\end{array}$ & mutations in PTPN11 & Other Mutations & $\begin{array}{l}\text { Previous } \\
\text { reference } \\
\text { (PMID) }\end{array}$ & Clonality \\
\hline 1 & 82 & M & bone, orbit & $\begin{array}{l}\text { Death } \\
5.14 \\
\text { months }\end{array}$ & & WT & NA & NA & \\
\hline 2 & 74 & M & Lymph Node & $\begin{array}{c}\text { Death } \\
8.5 \text { months }\end{array}$ & & WT & NA & NA & \\
\hline 3 & 1 & $\mathrm{~F}$ & $\begin{array}{l}\text { Lymph } \\
\text { Node, lung }\end{array}$ & $\begin{array}{c}\text { Death } \\
8.16 \\
\text { months }\end{array}$ & & WT & NA & NA & \\
\hline 4 & 63 & $\mathrm{~F}$ & liver & $\begin{array}{l}\text { Death } \\
13.96 \\
\text { months }\end{array}$ & CLL & PTPN11:chr12:112450451 A>G(91) & NA & NA & NA \\
\hline 5 & 25 & $\mathrm{M}$ & NA & NA & NA & WT & NA & NA & \\
\hline 6 & 42 & $\mathrm{~F}$ & brain & $\begin{array}{l}\text { Death } \\
26.88 \\
\text { months }\end{array}$ & & PTPN11:chr12:112450406 G>A(76) & NA & NA & \\
\hline 7 & 27 & $\mathrm{~F}$ & $\begin{array}{c}\text { brain/spinal } \\
\text { corde }\end{array}$ & $\begin{array}{l}\text { Death } \\
3.51 \\
\text { months }\end{array}$ & & WT & NA & NA & \\
\hline 8 & NA & $\mathrm{F}$ & NA & NA & NA & 010 & NA & NA & \\
\hline 9 & 42 & M & Lymph node & $\begin{array}{l}\text { Death } \\
60.91 \\
\text { months }\end{array}$ & LCH & WT & NA & NA & NA \\
\hline 10 & 61 & $\mathrm{~F}$ & $\begin{array}{l}\text { Digestive } \\
\text { tract }\end{array}$ & NA & & WT & NA & NA & \\
\hline 11 & 21 & $\mathrm{M}$ & $\begin{array}{c}\text { Skin, lymph } \\
\text { node }\end{array}$ & $\begin{array}{l}\text { Death } \\
14.26 \\
\text { months }\end{array}$ & & WT & NA & NA & \\
\hline 12 & 74 & $\mathrm{M}$ & $\begin{array}{l}\text { Lymph } \\
\text { node, } \\
\text { digestive }\end{array}$ & $\begin{array}{l}\text { Death } \\
4.72 \\
\text { months }\end{array}$ & & WT & NA & NA & \\
\hline
\end{tabular}




\begin{tabular}{|c|c|c|c|c|c|c|c|c|c|}
\hline & & & tract & & & & & & \\
\hline 13 & 8 & M & Lymph Node & $\begin{array}{l}\text { Death } \\
24.98 \\
\text { months }\end{array}$ & pre B ALL & WT & NA & NA & NA \\
\hline 14 & 78 & $\mathrm{~F}$ & $\begin{array}{c}\text { Bone, liver, } \\
\text { brain }\end{array}$ & $\begin{array}{l}\text { Death } \\
3.05 \\
\text { months }\end{array}$ & & PTPN11:chr12:112450385 G>A(69) & NA & NA & \\
\hline 15 & 81 & M & Lymph node & $\begin{array}{l}\text { Alive } \\
5.5 \text { years }\end{array}$ & & WT & $\begin{array}{c}\text { KRAS:chr12:25227341 T>G } \\
\text { (61) }\end{array}$ & NA & \\
\hline 16 & 66 & $\mathrm{~F}$ & $\begin{array}{l}\text { Lymph } \\
\text { node, } \\
\text { digestive } \\
\text { tract, liver }\end{array}$ & $\begin{array}{l}\text { Death } \\
9.3 \text { years }\end{array}$ & & WT & WT & NA & \\
\hline 17 & 4 & $\mathrm{~F}$ & \begin{tabular}{|c} 
Lymphe \\
node, lung. \\
Spleen, liver
\end{tabular} & $\begin{array}{l}\text { Death } \\
9 \text { days }\end{array}$ & TALL & WT & $\begin{array}{c}\text { KRAS:chr12:25245350 C>T } \\
\text { (12) }\end{array}$ & NA & NA \\
\hline 18 & 7 & M & $\begin{array}{l}\text { BM, liver, } \\
\text { spleen, LN }\end{array}$ & $\begin{array}{l}\text { Death } \\
6 \text { weeks }\end{array}$ & T ALL & WT & $\begin{array}{c}\text { KRAS:chr12:25245350 } \\
\text { C }>T(12) \\
\text { BRAF:chr7:140781617 C>A } \\
(464)\end{array}$ & 25833113 & yes \\
\hline 19 & 12 & M & $\begin{array}{l}\text { BM, skin, } \\
\text { liver, spleen }\end{array}$ & $\begin{array}{c}\text { Death } \\
10 \text { months }\end{array}$ & T ALL & WT & WT & 25833113 & yes \\
\hline
\end{tabular}

